\title{
Research on the Methods of Management of University Students in the Big Data Age
}

\author{
Yingying Luo \\ Sichuan University of Arts and Science, Dazhou, China \\ Email: 499166448@qq.com
}

How to cite this paper: Luo, Y.Y. (2021) Research on the Methods of Management of University Students in the Big Data Age. Open Access Library Journal, 8: e7411. https://doi.org/10.4236/oalib.1107411

Received: April 12, 2021

Accepted: May 11, 2021

Published: May 14, 2021

Copyright $\odot 2021$ by author(s) and Open Access Library Inc.

This work is licensed under the Creative Commons Attribution International License (CC BY 4.0).

http://creativecommons.org/licenses/by/4.0/

\section{(c) (i) Open Access}

\begin{abstract}
The world is in an age of digitalization. With the continuous development of data technology, it brings both challenges and opportunities to the management of university students. By analyzing the characteristics of the administration of students in colleges and universities, we can change the traditional educational management mode, actively adjust the working methods and strategies, grasp the development opportunities of Internet technology, and innovate the management method of student timely. This paper analyzes the difficulties faced by college administrators in the big data age, and then proposes to explore the methods of comprehensive construction of management, improvement of the effectiveness of management, and development of the standard of service. Based on the study of the path exploration of college student management in the big data age, it also puts forward countermeasures to solve the problems, so as to actively explore the path of college student management.
\end{abstract}

\section{Subject Areas}

Sociology

\section{Keywords}

Big Data Age, Colleges and Universities, Education and Management of Students, Path Exploration

\section{Introduction}

Viktor M. Schönberger, author of Big Data, believes that big data is a source of new knowledge and value creation. Big data is also a way to change markets, organizations, and the relationship between government and citizens [1]. People's life has been inseparable from information technology, and extensive informa- 
tion technology has provided convenience for life. The rapid development of information technology has promoted much progress of colleges and universities, with all aspects of informationization and digitalization in student management. "Big data age" provides new means and methods for students to understand the world and innovate the world, and, at the same time, broadens the channel for cultivating college students' self-reliance, self-improvement and scientific and technological innovation consciousness. On the other hand, the influx of a large number of western cultural trends and values has posed certain difficulties for the student management work in colleges and universities. In the big data age, we should innovate the management ideas and methods, give full play to the advantages of big data, and bring the opportunities to student management. By integrating all kinds of educational resources with big data analysis, under the guidance of Xi Jinping's new era socialism thought and with the goal of cultivating people by virtue, we should innovate the development mode of student work, change the service concept and improve the management level, and lay the foundation for further development in student management and service. Opportunities and challenges coexist. First of all, big data brings rich and varied data information for student management, which can further accurately analyze students' ideological dynamics, but increases the difficulty of technical processing. Secondly, it is convenient for administrators to accurately grasp the personalized education of students, but has brought a lot of information security risks, such as a variety of information leakage, network fraud, and deception on college students. Finally, it brings a brand new idea of management, but at the same time, it puts higher requirements for them, who lack professional skills in the application of big data technology. Therefore, this paper analyzes the difficulties faced by the management of college students in the age of big data, and then finds solutions to the problems, so as to promote the innovation and development of the management of college students.

\section{Difficulties of the Management of College Students in the Big Data Age}

The development of a country depends on the advancement of modern information technology, so as to the development of colleges and universities. In the management of student education, we can make full use of data analysis to integrate educational resources, analyze the ideological status and development of students, and take this as the starting point to understand students, so as to better carry out the management of student education. Opportunities and challenges coexist. The big data age brings opportunities as well as challenges to students management. According to Schönberger, the "father of big data", the big data age has influenced every aspect of the world, from business technology to medical care, government, education, economy, humanities and other fields of society. [1] The student management in colleges and universities must follow the law of student development, objectively analyze the challenges that big data age brings, actively deal with them, look for a way out from the perspective of development, and 
promote the integration and innovative development of student management.

1) The increase of difficulties in information management

The advent of big data age and its following big data technology, along with its characteristics of massiveness, complexity, diversity and cutting-edge, innovative and high-end technical attributes, are affecting people's cognition and thinking mode of the world, and are important carriers and basic sources for modern people to acquire knowledge and information. [2] The vigorous development of information technology and big data has facilitated the dissemination of some ideas that influence the formation of correct views among students. However, some ulterior motivated capitalists, adverse forces, organizations make troubles, make up false information, and try to mislead college students by spreading biased information that do harm to the reputation of our nation and using their characteristics of immaturity in the critical stage of their formation of correct values. It brings more difficulties for administrators in colleges and universities and causes troubles for college students to establish the correct views towards the society. It is not conducive to colleges and universities to play the function of ideological education, and requires higher standards for the quality and ability of administrators. For example, hackers have seriously damaged the security of network information platforms and the development and exploration of big data are also threatened by hacker attacks. Some criminals are benefited from selling personal information with some special technology to infiltrate into the data and information platform to steal confidential information and then sell at a certain price. He may even do the speculation to many buyers instead of one, which seriously affects the life of the victims. [3] On the other hand, in the big data age, there is a large amount of information within reach and the speed of information transmission is fast. There is not much difference between the timeliness of information obtained by administrators and students. As a result, educators lose their advantages in obtaining educational resources, and educators' authority is challenged. Students can find information needed on the Internet at any time, and compare, discuss and evaluate them, which brings challenges to the management of them.

2) Challenges in information security

Science and technology is a double-edged sword. The rapid development of information technology, on the one hand, has promoted the university information construction and development. On the other hand, it has caused network security problems. Due to the characteristics of fast, variety and complexity of information transmission, criminals have created a lot of digital viruses to attack systems in order to seek illegal interests. Frequent information attacks bring challenges to the information construction of colleges and universities, increase the difficulty of better maintaining the information of teachers and students, and pose obstacles for educators to utilize information to carry out their work.

3) The slowness and backwardness of colleges and universities in response to data and information 
In order to better manage the education of students, higher requirements are put forward for the informatization construction of colleges and universities. However, the current awareness of big data and the informatization construction level of colleges and universities are relatively lagging behind, which restricts the actual effect of the education management of students. Firstly, educators are not sufficiently aware of informatization, and fail to timely apply big data technology to work. Moreover, a large number of fragmented information pose higher requirements for educators to find the law of student development by using information. Secondly, the information construction of colleges and universities is not perfect enough and systematic guidance construction is insufficient, which affects the practical result of student education management.

\section{Innovative Development of University Student Education Management in Big Data Age}

1) We should attach great importance to forming resultant strength and comprehensively constructing smart management system of student management

a) To build digital campus and improve the digital level of student education management with big data. "The features of a smart campus include full coverage of information services, autonomy in information services, intelligent equipment supervision, and flexibility in data statistics." [4] The management of university student should be improved and changed in accordance with the time. Educators should give full play to the role of big data in student education management. In the first place, the management work of student education is relevant to the whole administration system, and each administrative department is serving for the students. In order to play the linkage role of departments, a sharing platform for education can be built to improve work efficiency. It is necessary to strengthen top-level design and overall planning, update and track student related information in a timely manner, effectively manage the platform of student education management system, and further promote information construction. In addition, colleges and universities should strengthen the training of data knowledge for administrators, so as to improve the top-level design and overall planning of the construction of smart campus, build a smart learning and management system with comprehensive coverage, timely update, dynamic tracking and immediate feedback of data information and make full use of big data resources to promote the construction of smart learning and education management, such as students' election on excellence and awards, competitions and other activities.

b) To improve the awareness of big data among student management staff. The improvement of information literacy and big data awareness is the foundation of student management work. On the one hand, administrators should be trained to enhance their data awareness and fully explore their ability to analyze, utilize and coordinate big data. The convenience of data should be recognized by management staff. On the other hand, it is important to improve the compre- 
hensive quality of information staff and strengthen their ability to effectively analyze the management of students with big data.

c) All administrative departments in the university should form joint efforts to strengthen the construction of information security system. In big data age, information security is particularly important. Information security is related to everyone in all aspects. Science and technology is a double-edged sword. It is necessary to make accurate use of information to better manage students and strengthen the protection of information platforms. Research shows that information security is a key issue to be solved urgently for the development of the current big data industry. In particular, "personal data privacy leaks have become the vital issue of network security in China recently". It is surprising that the leakage is in wide range, large number, rapid spread and centralized outbreak [5]. Once relevant data is leaked, the overall work of the university will be affected. It is necessary to coordinate departments to form a joint force for information construction, and clarify responsibilities at the same time. With the security system, the potential risks and related hidden dangers of big data of management system will be reduced.

2) To innovate the mechanism, analyze the characteristics and enhance the effect of management

a) It is burdensome to manage the task of student education and the requirement is high. To do well in the work of student education management, we must first clarify its characteristics and improve the effectiveness. The work of student education management includes both the education and the management of students. It is important to comprehensively analyze the characteristics of various work, grasp the work development mode, and carry out the work innovatively in combination with the characteristics and conditions of students. In this way, the characteristics of student management are analyzed through big data, and the data are used to carry out surveys to analyze students' specific views on award setting, evaluation methods and the setting of scholarships and grants. In brief, we should, on the base of student-orientation, accurately formulate all kinds of scientific and reasonable programs, carefully implement the management of students, and improve its effectiveness.

b) To analyze hotly-discussed and difficult issues that students are concerned about with big data. Educators are obliged to predict the tendency of their work, accurately carry out the management of students, timely find loopholes in it, plan in advance, and correctly analyze and judge the prospective of the management work. Through the analysis of students' thoughts, the difficult and key issues can be predicted, so as to improve work efficiency. By analyzing relevant social data of students, such as Weibo, WeChat, QQ, bulletin board and other network platforms, administrators can understand students' demands in-depth, further grasp the ideological tendency of students, and carry out student management and service work precisely.

3) To integrate data, attach importance to evaluation, and improve service methods for students 
a) To analyze the characteristics of students' needs and add or subtract relevant work in time. The focus of management work of student management should be adjusted to better solve the key points of students' problems and substantive difficulties based on the interest of students. Reasonable adjustment of working strategies and the use of big data can effectively improve students' working efficiency and enhance the influence of student management. Considering the characteristics of students, it is important to understand students' thoughts, and implement the management work to practice.

b) To Improve the evaluation mechanism of students on management. Administrators should focus on student evaluation, analyze students' concerns on management system and relevant suggestions with big data, so as to accurately analyze the work of relevant administrative departments, and timely improve methods based on students' suggestions. To improve the efficiency of management system and pay attention to the key points of student evaluation to improve the working methods and enhance the practical effect.

\section{Conclusion}

With the development of science and technology, information technology is changing rapidly, and the application range and degree of big data are gradually expanding and deepening. In the age of big data, it is an opportunity as well as a challenge for administrators in colleges and universities. As educators, we should convert challenges into opportunities in the new age, combine the management work with the current situation, find the characteristics of students, and explore the law of student management. Furthermore, it is significant to actively carry out management and service work with big data, optimize management mode, enhance education effect, improve service ability, and promote student management to a new level.

\section{Conflicts of Interest}

The author declares no conflicts of interest regarding the publication of this paper.

\section{References}

[1] Mayer-Schönberger, V. (2013) Big Data: A Revolution that Will Transform How We Live, Work, and Think. Zhejiang People's Press, Hangzhou.

[2] Liang, J.F. and Qi, Z.H. (2013) Adaptation and Innovation: Ideological and Political Education in Universities in the Big Data Age. Research of Ideological Education, 6, 63-67.

[3] Xiao, J. (2021) Information Security Opportunities and Challenges in the Big Data Age. Shihezi Science and Technology, 4, 45-46.

[4] Zhang, J. (2020) Construction of Support Platform of Intelligent Campus Informationization and Operation. Electronic Technology and Software Engineering, 12, 133-134.

[5] Wang, Z. (2014) Regulation of Personal Data in the Big Data Age. Social Sciences Academic Press, Beijing. 